\title{
Delayed Arterial Occlusion Presenting as Foot Drop Following Primary Total Knee Arthroplasty in a Varus Knee: A Case Report and Review of the Literature
}

\author{
Clayton Del Prince John Reza Matthews Matthew Phillips \\ Jacobs School of Medicine and Biomedical Sciences, Buffalo, NY, USA
}

Keywords

Total knee arthroplasty · Vascular · Arterial injury · Varus knee

\begin{abstract}
We present a 69-year-old male with osteoarthritis of a varus mechanically aligned left knee that developed delayed arterial thrombosis after primary total knee arthroplasty (TKA) requiring stenting and subsequent trans-metatarsal amputation. This case is unique since initial presentation involved neurologic instead of ischemic changes. We also performed a literature review of arterial injuries in primary TKA. This case highlights the importance of maintaining a high clinical suspicion for vascular insult in patients undergoing correction of varus malalignment with initial complaints of neurologic dysfunction.
\end{abstract}

\section{Introduction}

Iatrogenic vascular injury in total knee arthroplasty (TKA) can have devastating results. The incidence of vascular complications is between 0.06 and $0.2 \%$ [1-4]. These complications include vessel occlusion, transection, arteriovenous fistula, and aneurysm/pseudoaneurysm formation, among others [5]. Complications commonly result from indirect trauma such as mechanical stretching/compression from retractors but can occur from direct injuries with the saw blade $[4,6,7]$. The reported sequela includes neurologic deficit, compartment syndrome, amputation, infection, and death $[4,7,8]$.

Preoperative screening for underlying peripheral vascular disease may help identify higher risk patients $[9,10]$. It is essential for surgeons to understand the risk factors, preventative 


\section{Case Reports in Orthopedic Research}
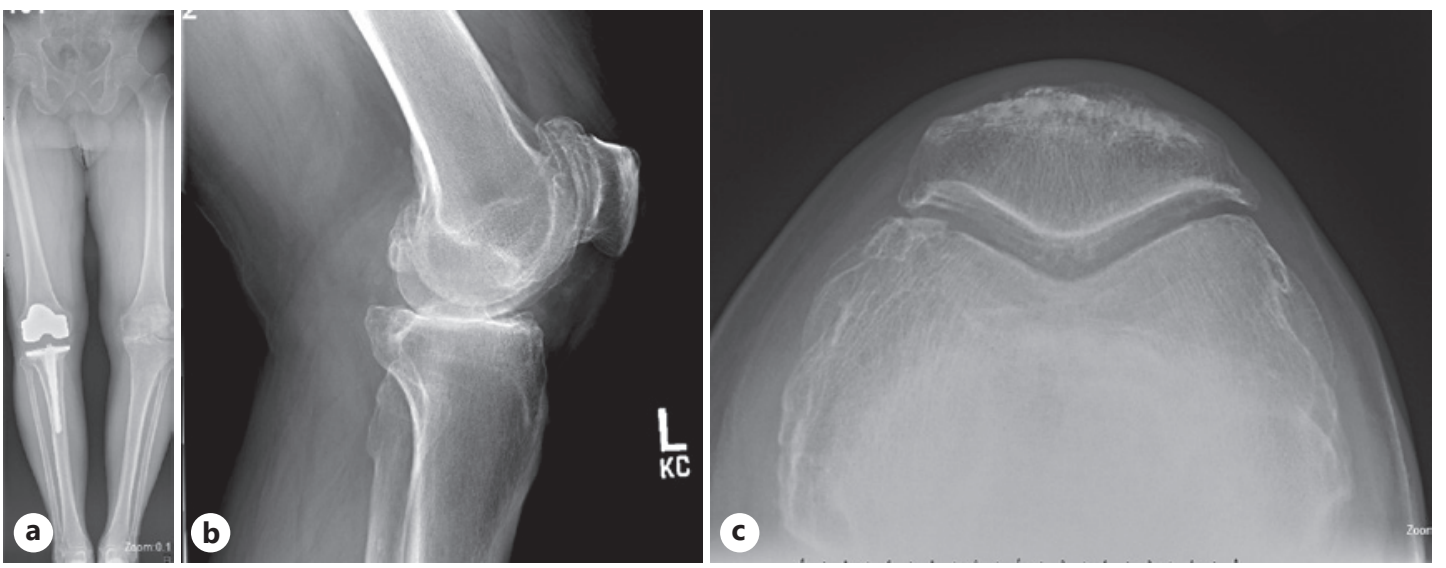

Fig. 1. Full-length standing (a), lateral (b), and sunrise (c) left knee X-rays demonstrating a 15-degree varus mechanical axis alignment on the left with complete loss of articular cartilage along the medial and patellofemoral compartments as well as osteophyte formation. On the right, there is a stemmed total knee component in good position with an overall 2-degree varus mechanical axis alignment.

measures, recognition, and management of arterial injuries. We present a case report of a 69-year-old male with osteoarthritis of a varus mechanically aligned left knee that developed delayed arterial thrombosis requiring stenting and subsequent trans-metatarsal amputation (TMA). We also performed a review of the literature pertaining to arterial injuries in primary TKA.

\section{Methods}

To ascertain all studies pertaining to arterial injuries in primary TKAs, we performed a literature search of articles published in English between 1985 and February 2020. We searched PubMed, Embase, and the Cochrane database. The search terms were ("primary total knee" or "TKA") and ("vascular" or "vascular complication"). We excluded abstracts, narrative reviews, articles not written in English, commentaries, and topics not focused on arterial complications. The results of the literature search were independently reviewed by 2 authors in detail and summarized. In total, 187 studies were identified, but 41 remained after exclusion.

\section{Case Report}

The patient was a 69-year-old male with hypertension, coronary artery disease, hypothyroidism, gastric reflux, and prior right superficial femoral artery (SFA) stenting on Aspirin/ Plavix with left knee pain. He had an antalgic gait with 5-110 degrees of knee flexion with pain and crepitation. Palpable dorsalis pedis (DP) and posterior tibial (PT) pulses were present with a warm, well-perfused foot. He had a prior right TKA that was uncomplicated. Imaging studies demonstrated degenerative arthritis with a varus mechanical alignment and mild vascular calcification (Fig. 1).

After failed nonoperative management the patient elected to proceed with surgery. He underwent a left Mako robotic-assisted TKA. Intraoperatively, the tourniquet was inflated to

\section{Karger'}




\section{Case Reports in Orthopedic Research}
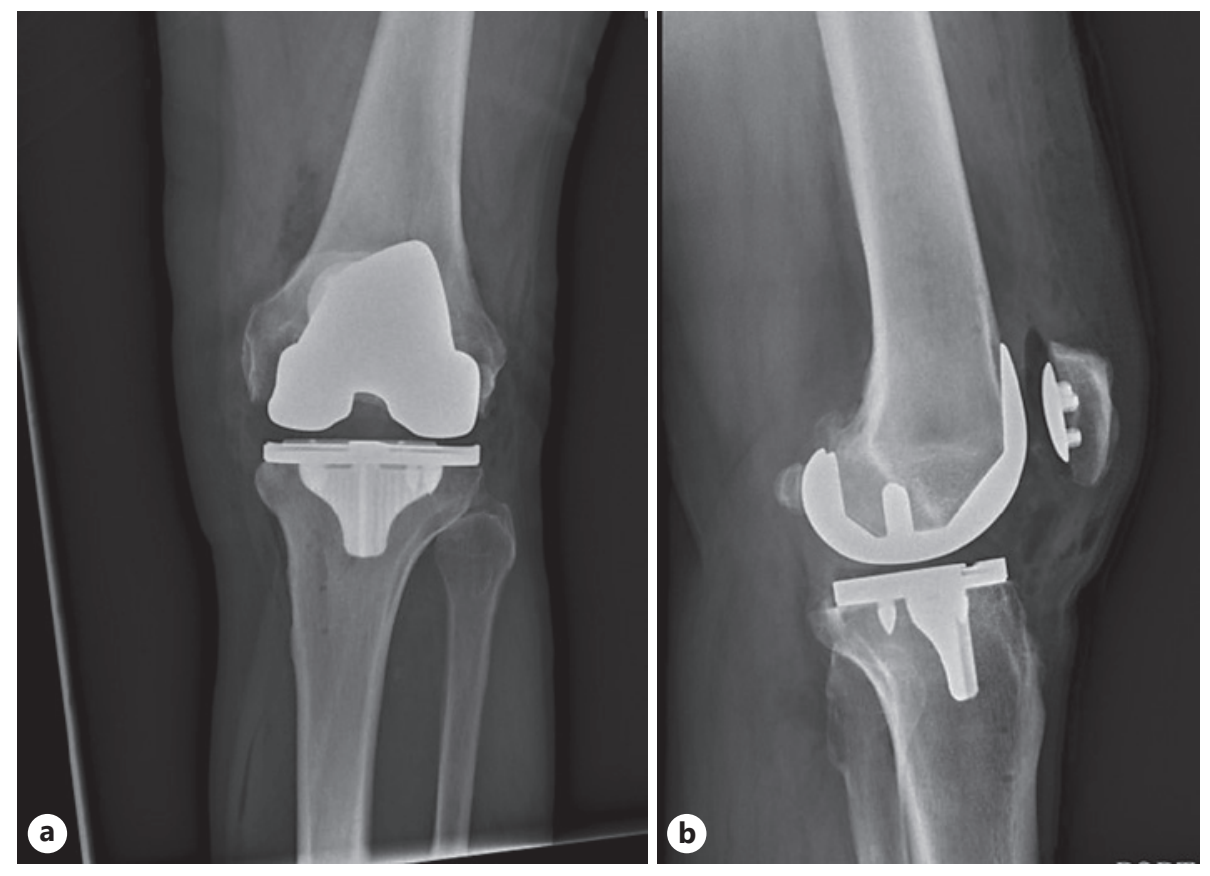

Fig. 2. Immediate postoperative AP (a) and lateral (b) X-rays of the left knee demonstrating total knee replacement.

$250 \mathrm{~mm} \mathrm{Hg}$ for a total of $36 \mathrm{~min}$. Stryker Triathlon CR uncemented implants were used. Postclosure motion demonstrated 0-130 degrees of flexion. There were no recognized complications, and he had a palpable DP pulse. X-rays were obtained in recovery (Fig. 2).

In recovery, the patient was found to have a partial peroneal and tibial nerve palsy. The ted stocking was removed and his knee was flexed over a pillow. DP pulse was palpable. The next morning, he had near-complete peroneal and tibial nerve palsies with weak tibialis anterior (TA), extensor hallucis longus (EHL), flexor hallucis longus (FHL), and gastro-soleus (GS) function. He also had diminished sensation along the lateral aspect of the shin and dorsal foot. He continued to have a palpable DP pulse with brisk capillary refill. He was restarted on his home anticoagulation regimen. On postoperative day 2, the patient had worse TA, EHL, FHL, and GS function with unchanged paresthesias. He continued to have a palpable DP pulse and was discharged home.

He was seen in office 1 week later with foot swelling with diminished sensation along the dorsal medial 3 digits with continued weakness in TA, EHL, FHL, and GS. His incision was clean with no surrounding erythema. Active ROM was 5-100 degrees of flexion. His calf was soft and nontender. He was started on Gabapentin due to persistent nerve pain and physical therapy to prevent achilles contracture.

The following week, the patient called the office due to persistent swelling and foot blistering. He was given a prescription for Silvadene and instructed to keep his leg elevated. He presented for follow-up 1-month post-op with extensive erythema over the ankle dorsally and plantarly to the level of the tarsometatarsal joint with overlying blisters. He had diminished sensation along the dorsal and plantar aspect of his foot. The toes were swollen and cold with no palpable DP or PT pulse. Repeat imaging demonstrated stable bilateral total knee replacements (Fig. 3). The patient was emergently sent to the vascular laboratory where noninvasive arterial studies demonstrated an ankle-brachial index (ABI) of 0.27 on the left relative to 0.9 on the right. A duplex scan revealed extensive arterial occlusive disease with 
Fig. 3. Long-standing lower extremity X-ray demonstrating stable bilateral total knee replacements.

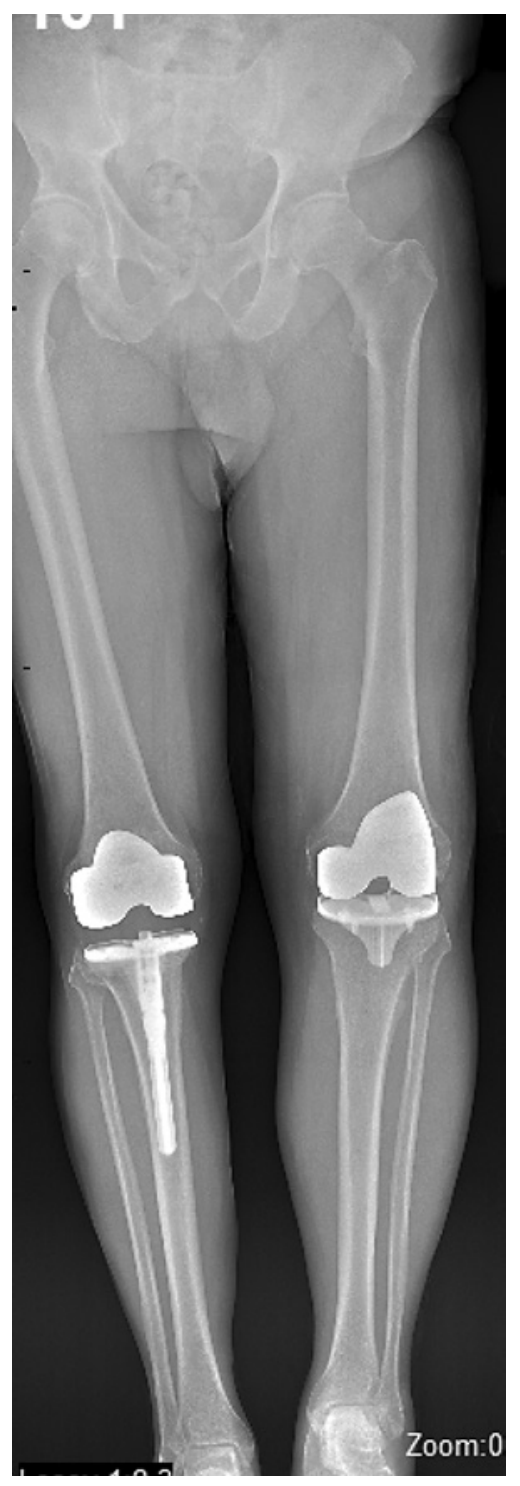

severe flow reduction in the SFA and popliteal artery with collateral flow. Angiogram demonstrated patent common, external, iliac, and deep femoral arteries. There was occlusion of the proximal SFA with re-constitution in the middle third with extensive collateral circulation (Fig. 4a). The popliteal artery had multiple areas of stenosis involving the supra-/infrageniculate regions and takeoff of the anterior tibial artery. All lesions appeared to be standard atherosclerotic disease without evidence of intimal trauma. He underwent angioplasty of the superficial femoral, popliteal, tibio-peroneal trunk, and posterior tibial (PT) arteries and stenting of the popliteal and SFA. Repeat angiogram demonstrated no residual stenosis (Fig. 4b). The patient then underwent irrigation and debridement of his left foot. Over the next week, he had repeated foot debridements due to poor healing and eventually underwent a TMA.

He was seen in the office for 4 months following the index procedure. The knee was stable with 5-115 degrees of flexion. His foot demonstrated interval healing but continued to lack active dorsiflexion and his passive maximum dorsiflexion was 10 degrees of plantar flexion.

At his 1-year follow-up, the patient continued to have no active ankle dorsiflexion. His passive dorsiflexion was 5 degrees of plantar flexion. The foot amputation wound was healed. 
Fig. 4. a Angiogram of the proximal femoral vasculature demonstrating severe stenosis of the superficial femoral artery. b Angiogram demonstrating a patent SFA status post angioplasty and stenting. SFA, SFA, superficial femoral artery.
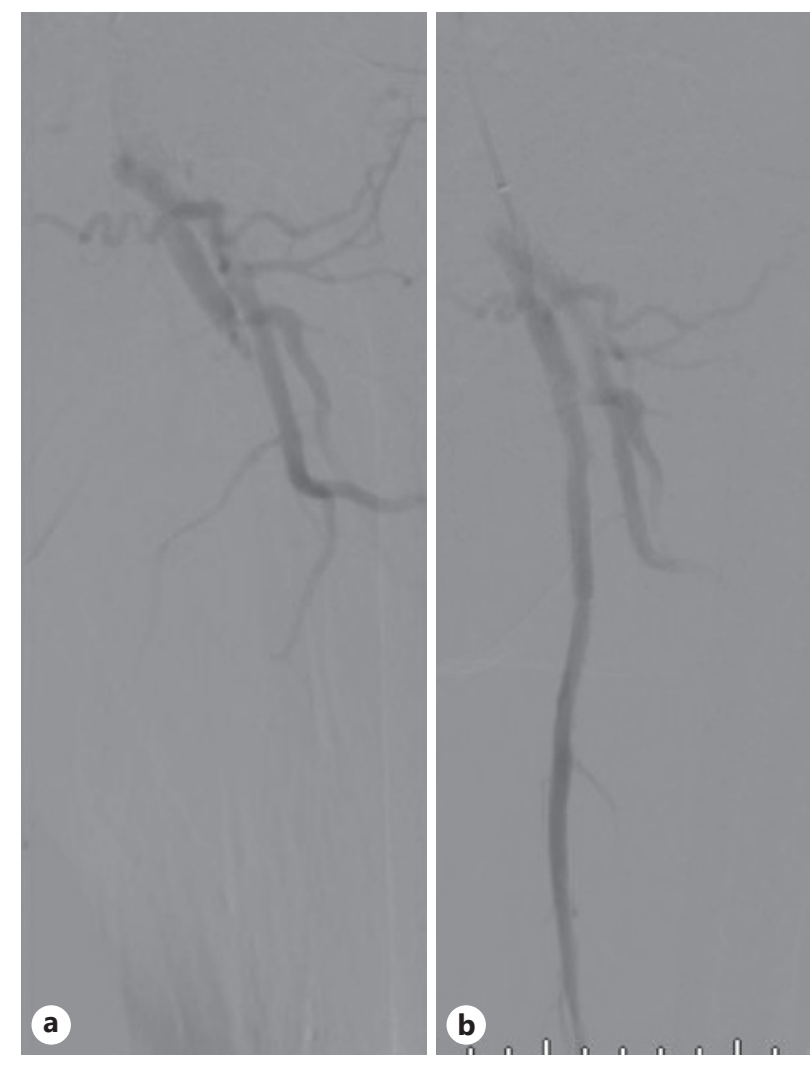

His knee was benign and demonstrated 5-115 degrees of flexion. He was offered a referral to a foot-ankle specialist but was happy with his progress.

\section{Discussion}

Vascular complications following TKA can have devastating results. Early diagnosis and treatment are essential for limb salvage [7]. A review of arterial injuries after TKA by Li et al. [11] found pulselessness to be the most common presentation usually occurring within $24 \mathrm{~h}$. We presented a unique case of delayed arterial thrombosis after primary TKA with initial complaints of neurologic dysfunction that required a TMA.

Risk factors for arterial complications include peripheral arterial disease (PAD), prior bypass, arterial calcification on radiographs, revision surgery, weight loss, renal failure, coagulopathy, metastatic cancer, and Afro-Caribbean origin [3,12]. In a series of acute arterial thromboses, ischemic complications occurred only in patients with atherosclerotic disease [2]. Due to this higher risk in patients with atherosclerotic disease, Papadopolous et al. [5] recommended vascular consultation. Our patient had several risk factors including vascular calcification on radiographs and peripheral vascular disease with previous contralateral stenting.

The use of a tourniquet in TKA has been a topic of debate. The force generated by tourniquet application may fracture a calcified artery resulting in plaque embolization or anchor the SFA increasing the risk of traction injuries during knee manipulation. Tourniquets have also been reported to cause thrombosis of the SFA or develop thrombosis in preexisting popliteal aneurysms due to the low flow state [8]. Although tourniquet-related complications

\section{Karger's}


are rare, they are potentially limb and life-threatening. Potential complications include arterial compromise, pulmonary edema, neurologic injury, pulmonary emboli, and muscle injury. One author recommended avoiding a tourniquet in patients with preoperative ABIs less than 0.50 , radiographic evidence of vascular calcification, lack of palpable pedal pulses, or known peripheral atherosclerotic disease [2].

The most common presenting symptoms after arterial injury following TKA include pulselessness, poikilotherm, pain, paresthesia, pallor, poor capillary refill, paralysis, decreased ABI, mottling, swelling, blistering, and necrosis [11]. Motor weakness can also be a sign of vascular injury. Most peroneal palsies are experienced after correcting valgus deformities, but our patient had a $15^{\circ}$ varus mechanical alignment [13]. Our patient's initial postoperative complaint was neurologic similar to one of the patients in the Padegimas etal. [14] case series who had a peroneal nerve palsy along with vascular injury. This series included a vascular calcification score according to the Iijima scale [15]. Our patient's preoperative imaging demonstrated a vascular calcification score of 1 . When performing arthroplasty procedures in patients with calcified vessels and significant deformity, the surgeon must remain highly suspicious of vascular insult.

Early diagnosis of vascular injury requires meticulous neurovascular examination, with greater emphasis in high-risk populations. Regarding management in our case, preoperative Doppler scan should have been considered given the previous history of occlusion. As blistering can be associated with vascular injury or compartment syndrome, vascular evaluation at the time of this finding could have been advised. At our institution, we now obtain noninvasive arterial studies and vascular consultations for patients with postop palsies that have undergone correction of varus malalignment. With an increasing number of TKAs performed on an outpatient basis, there is concern over limited serial neurovascular monitoring [16]. Orthopedic surgeons should carefully select candidates for outpatient TKAs.

We present a review of the literature pertaining to arterial injuries following primary TKA (Table 1). The studies included in this review include case reports, case series, and systematic reviews. The purpose of this review is to outline the comorbidities, timing, diagnostic studies, treatments, and outcomes that have been reported. The time to diagnosis of arterial injury ranged from intraoperative to 3 years post-op for aneurysm $[12,19]$. The diagnoses were made through a combination of physical exam findings and diagnostic tests. Diagnostic investigations included ABI, Doppler/duplex studies, and angiograms [12, 25, 36]. Treatments included observation, direct repair, angioplasty, stenting/bypass, thrombectomy, endarterectomy, coil embolization, ultrasound compression, fistula resection, and amputation $[4,12,14,18,22,25,42]$. Outcomes ranged from complete resolution of symptoms to amputation and mortality $[4,36,46]$. This review shows that the majority of arterial complications are diagnosed within the first few days after surgery and are more common in patients with a history of hypertension or coronary artery disease. In comparison with these cases, our patient's diagnosis was delayed compared to the majority but still within what has been previously reported. Most patients in this review presented with early findings of a cold, pulseless limb, while our patient had early neurologic findings with delayed loss of pulse. This review agrees with the previous literature that has shown there is no consensus on optimum management and intervention must be determined by the specific pathology [12].

\section{Conclusion}

Initial presentation of vascular complications following primary TKA may include neurologic findings as opposed to ischemia. This case highlights the importance of maintaining a high clinical suspicion for vascular insult in patients that undergo correction of varus malalignment with initial complaints of neurologic dysfunction.

\section{Karger'}


Case Reports in Orthopedic Research
Case Rep Orthop Res 2021;4:11-23 DOI: 10.1159/000511967

(c) 2021 The Author(s). Published by S. Karger AG, Basel
www.karger.com/cio

Del Prince et al.: Delayed Arterial Occlusion after TKA

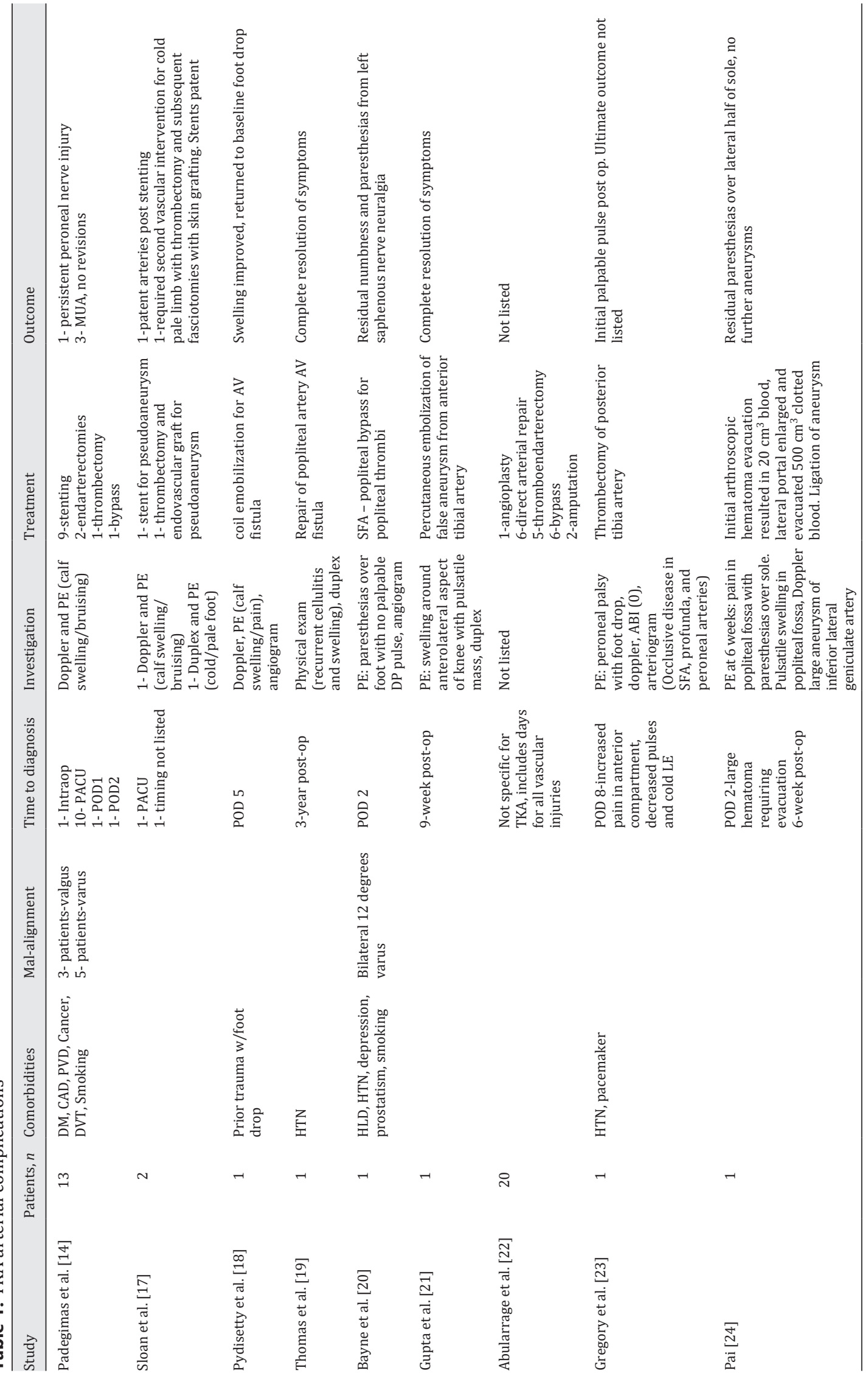


Case Reports in Orthopedic Research
Case Rep Orthop Res 2021;4:11-23 DOI: 10.1159/000511967

(c) 2021 The Author(s). Published by S. Karger AG, Basel www.karger.com/cio

Del Prince et al.: Delayed Arterial Occlusion after TKA

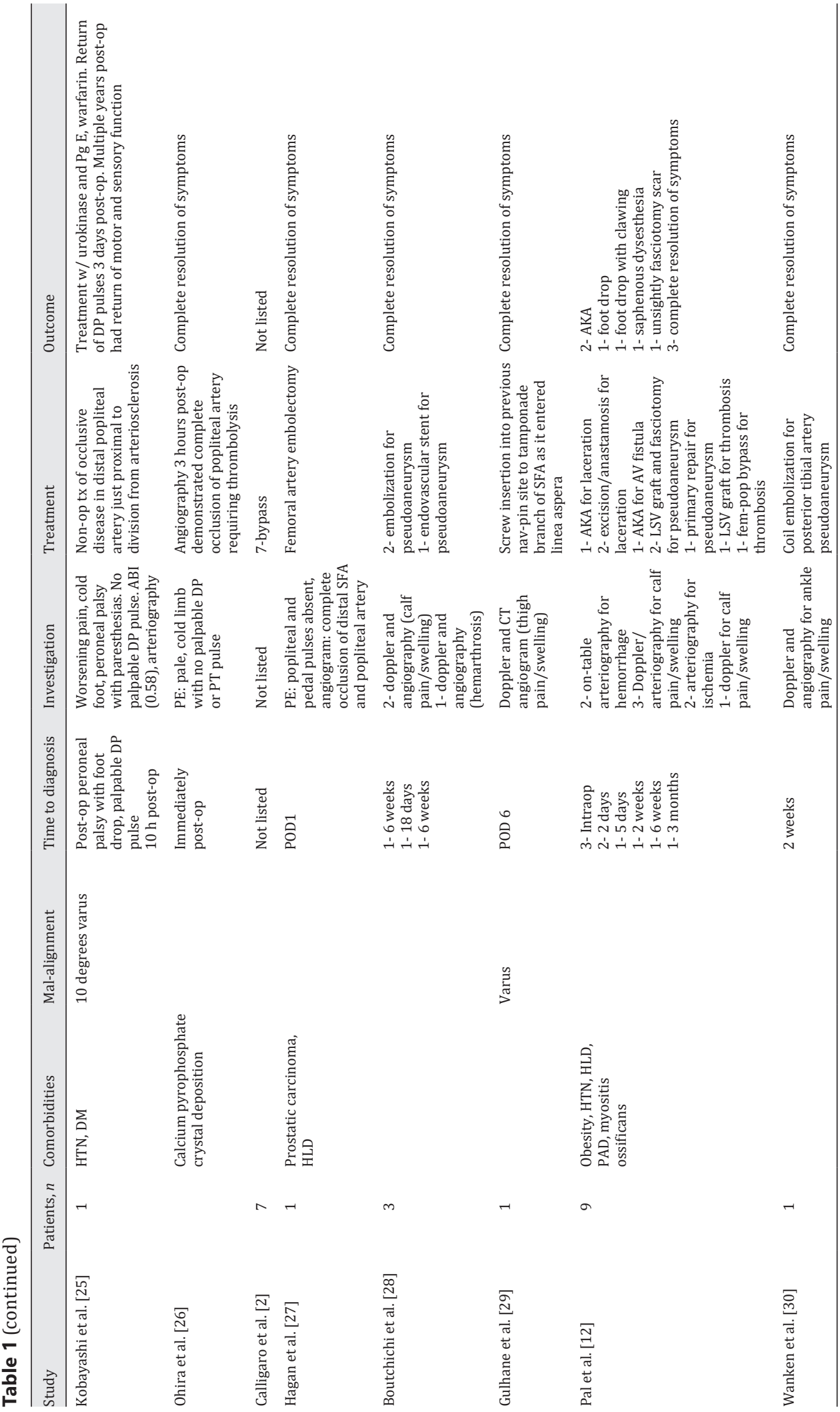

Karger' 
Case Reports in Orthopedic Research
Case Rep Orthop Res 2021;4:11-23 DOI: 10.1159/000511967 (c) 2021 The Author(s).P
www.karger.com/cio

Del Prince et al.: Delayed Arterial Occlusion after TKA

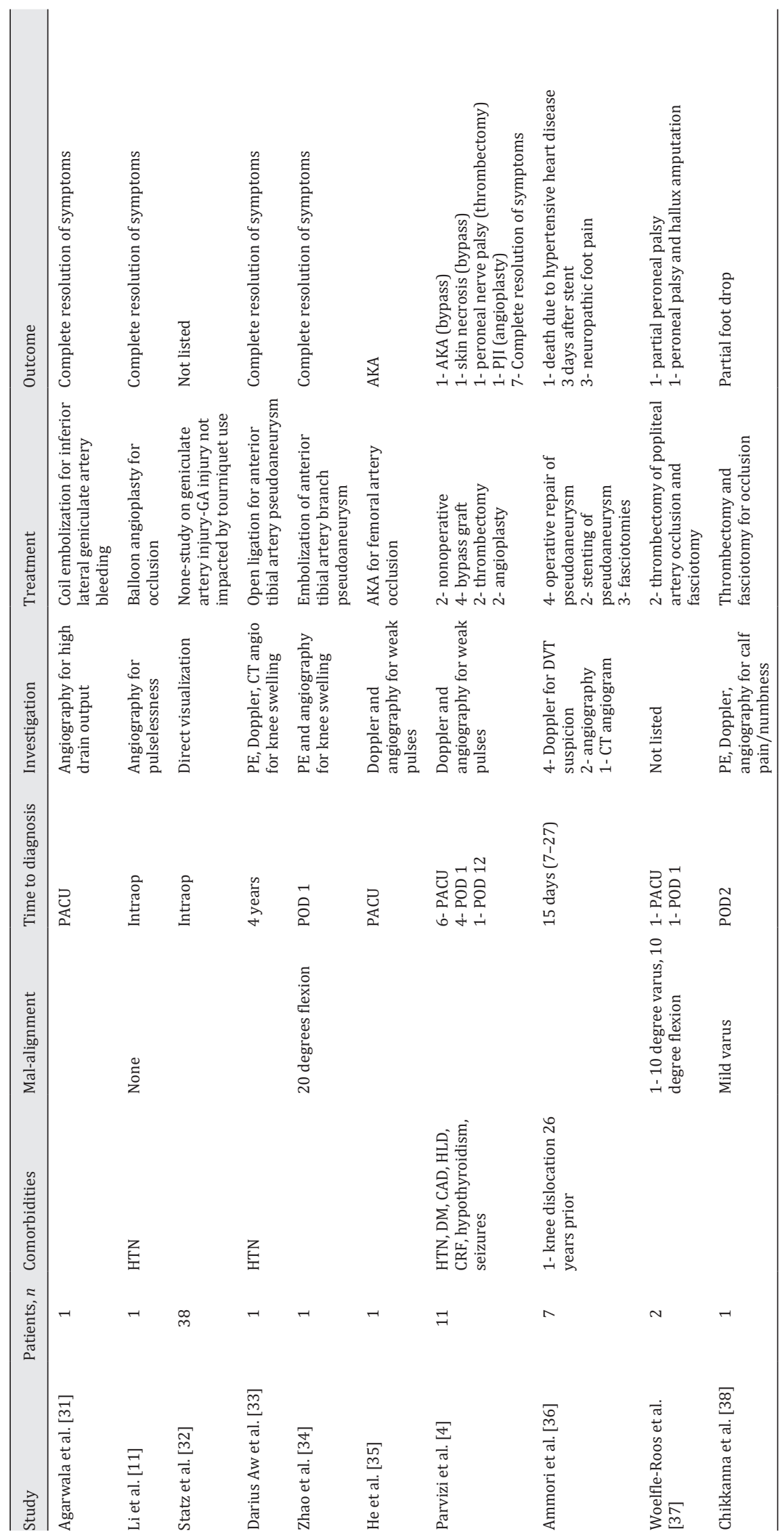

Karger' 
Case Reports in Orthopedic Research
Case Rep Orthop Res 2021;4:11-23 DOI: $10.1159 / 000511967$ (c) www.karger.com/cio

Del Prince et al.: Delayed Arterial Occlusion after TKA

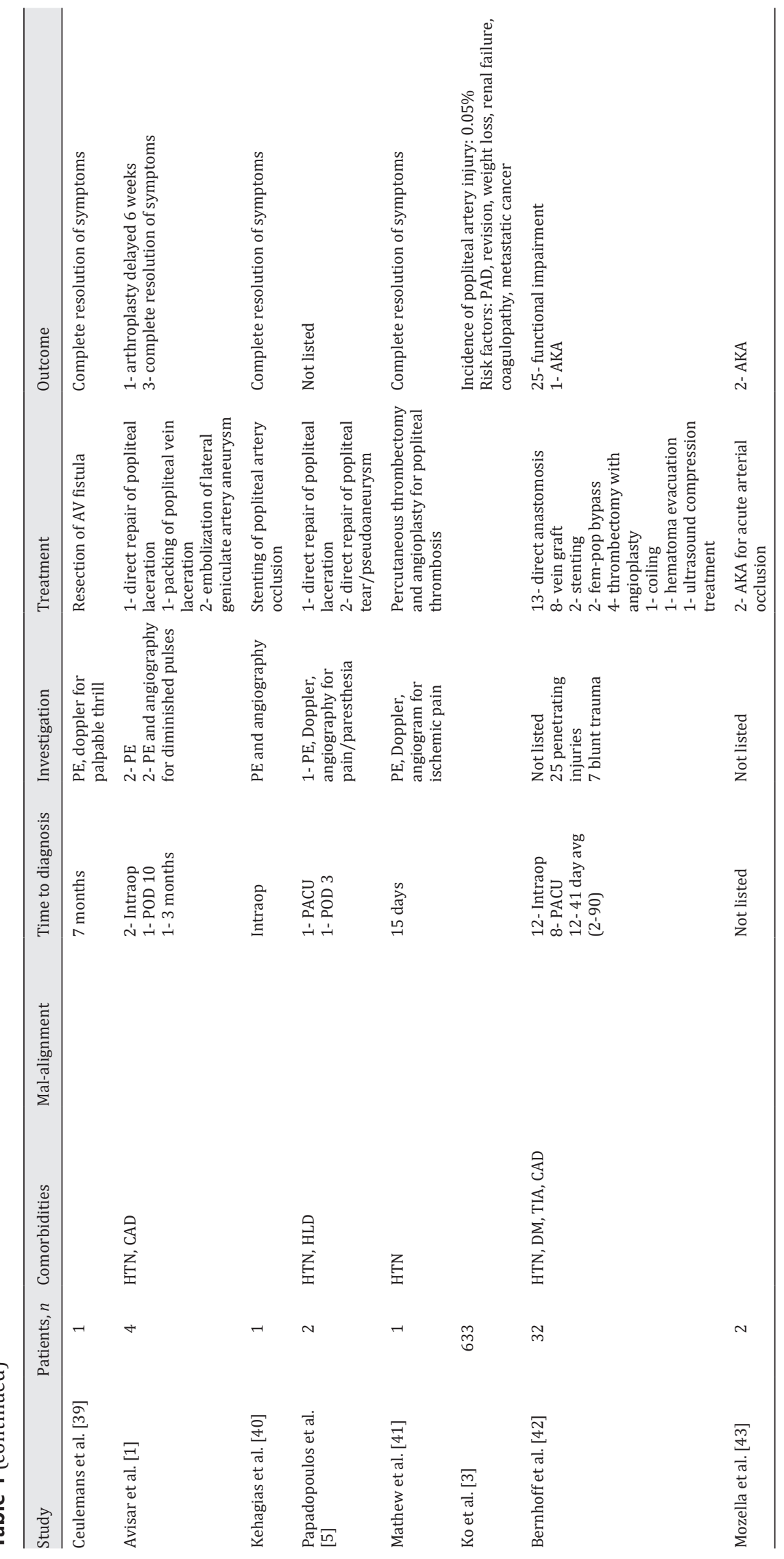

Karger' 
Case Reports in Orthopedic Research

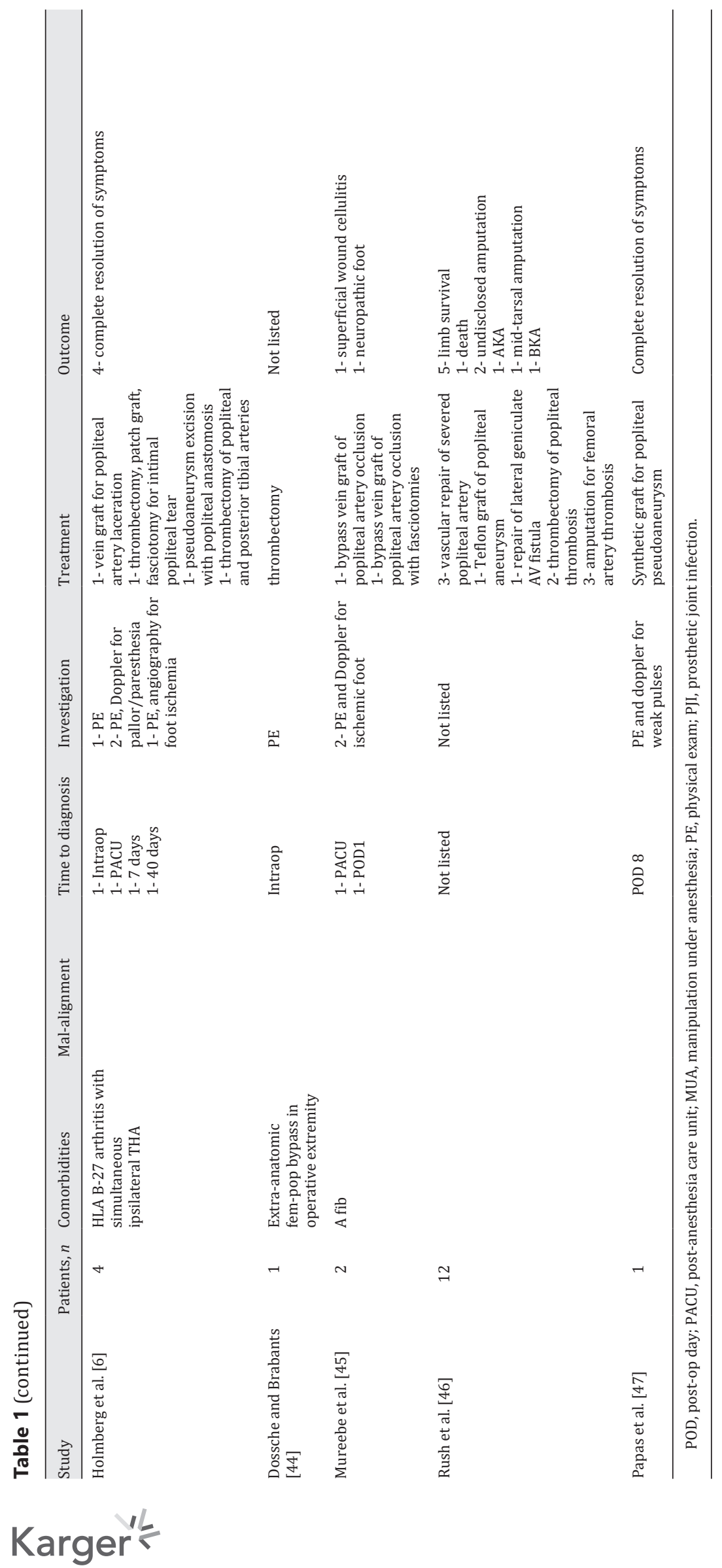


Case Reports in Orthopedic Research

\begin{tabular}{l|l}
\hline Case Rep Orthop Res 2021;4:11-23 \\
\hline DOI: 10.1159/000511967 & $\begin{array}{l}\text { @ 2021 The Author(s). Published by S. Karger AG, Basel } \\
\text { www.karger.com/cio }\end{array}$ \\
\hline
\end{tabular}

Del Prince et al.: Delayed Arterial Occlusion after TKA

\section{Statement of Ethics}

Written informed consent was obtained from the patient for the purposes of publication of this case report and the accompanying images.

\section{Conflict of Interest Statement}

Dr. Phillips: paid consultant for Stryker Orthopedics. Paid consultant for Smith \& Nephew Orthopedics.

\section{Funding Sources}

The authors did not receive any funding.

\section{Author Contributions}

Dr. Clayton Del Prince participated in the literature review, drafted the manuscript, and performed revisions. Dr. John Matthews performed the literature search, created the tables, and assisted in the manuscript drafting. Dr. Matthew Phillips provided the case and was instrumental in article selection and review. He participated in manuscript drafting as well as final revisions and edits.

\section{References}

1 Avisar E, Elvey MH, Bar-Ziv Y, Tamir E, Agar G. Severe vascular complications and intervention following elective total hip and knee replacement: a 16-year retrospective analysis. J Orthop. 2015;12(3):151-5.

2 Calligaro KD, DeLaurentis DA, Booth RE, Rothman RH, Savarese RP, Dougherty MJ. Acute arterial thrombosis associated with total knee arthroplasty. J Vasc Surg. 1994;20(6):927-32.

3 Ko LJM, DeHart ML, Yoo JU, Huff TW. Popliteal artery injury associated with total knee arthroplasty: trends, costs and risk factors. J Arthroplasty. 2014;29(6):1181-4.

4 Parvizi J, Pulido L, Slenker N, Macgibeny M, Purtill JJ, Rothman RH. Vascular injuries after total joint arthroplasty. J Arthroplasty. 2008;23(8):1115-21.

5 Papadopoulos DV, Koulouvaris P, Lykissas MG, Giannoulis D, Georgios A, Mavrodontidis A. Popliteal artery damage during total knee arthroplasty. Arthroplast Today. 2015;1(3):53-7.

6 Holmberg A, Milbrink J, Berqqvist D. Arterial complications after knee arthroplasty: 4 cases and a review of the literature. Acta Orthop Scand. 1996;67(1):75-8.

7 Bernhoff K, Björck M. Iatrogenic popliteal artery injury in non arthroplasty knee surgery. Bone Joint J. 2015; 97-B(2):192-6.

8 Da Silva MS, Sobel M. Popliteal vascular injury during total knee arthroplasty. J Surg Res. 2003;109(2):170-4.

9 Barrack RL, Butler RA. Avoidance and management of neurovascular injuries in total hip arthroplasty. Instr Course Lect. 2003;52:267-74.

10 Smith DE, McGraw RW, Taylor DC, Masri BA. Arterial complications and total knee arthroplasty. J Am Acad Orthop Surg. 2001;9(4):253-7.

11 Li Z, Xiang S, Bian Yy, Feng B, Zeng R, Weng Xs. Diagnosis and treatment of arterial occlusion after knee arthroplasty: the sooner, the better. Orthop Surg. 2019;11(3):366-72.

12 Pal A, Clarke JMF, Cameron AEP. Case series and literature review: Popliteal artery injury following total knee replacement. Int J Surg. 2010;8(6):430-5.

13 Schinsky MF, Macaulay W, Parks ML, Kiernan H, Nercessian OA. Nerve injury after primary total knee arthroplasty. J Arthroplasty. 2001;16(8):1048-54.

14 Padegimas EM, Levicoff EA, McGinley AD, Sharkey PF, Good RP. Vascular complications after total knee arthroplasty: a single institutional experience. J Arthroplasty. 2016;31(7):1583-8.

15 Iijima K, Hashimoto H, Hashimoto M, Son BK, Ota H, Ogawa S, et al. Aortic arch calcification detectable on chest $\mathrm{X}$-ray is a strong independent predictor of cardiovascular events beyond traditional risk factors. Atherosclerosis. 2010;210(1):137-44. 
16 Krause A, Sayeed Z, El-Othmani M, Pallekonda V, Mihalko W, Saleh KJ. Outpatient total knee arthroplasty: are we there yet? (Part 2). Orthop Clin North Am. 2018;49(1):7-16.

17 Sloan K, Mofidi R, Nagy J, Flett MM, Chakraverty S. Endovascular treatment for traumatic popliteal artery pseudoaneurysms after knee arthroplasty. Vasc Endovascular Surg. 2009;43(3):286-90.

18 Pydisetty RV, Gillies RM. Popliteal A-V fistula with pseudo-aneurysm: a complication following total knee arthroplasty. Eur J Trauma Emerg Surg. 2008;34(4):414-7.

19 Thomas R, Agarwal M, Lovell M, Welch M. An unusual presentation of a popliteal arteriovenous fistula after primary total knee arthroplasty. J Arthroplasty. 2008;23(6):945-8.

20 Bayne CO, Bayne 0, Peterson M, Cain E. Acute arterial thrombosis after bilateral total knee arthroplasty. J Arthroplasty. 2008;23(8):1239.e1-.e6.

21 Gupta R, Chitre A, Ryan W. False aneurysm of the anterior tibial artery following total knee arthroplasty. Acta Orthop Belg. 2008;74(1):128-31.

22 Abularrage CJ, Weiswasser JM, DeZee KJ, Slidell MB, Henderson WG, Sidawy AN. Predictors of lower extremity arterial injury after total knee or total hip arthroplasty. J Vasc Surg. 2008;47 (4):803-7.

23 Gregory PC, Rogic R, Eddington C. Acute arterial occlusion after total knee arthroplasty. Am J Phys Med Rehabil. 2006;85(11):924-6.

24 Pai VS. Traumatic aneurysm of the inferior lateral geniculate artery after total knee replacement. J Arthroplasty. 1999;14(5):633-4.

25 Kobayashi S, Isobe K, Koike T, Saitoh S, Takaoka K. Acute arterial occlusion associated with total knee arthroplasty. Arch Orthop Trauma Surg. 1999;119(3):223-4.

26 Ohira T, Fujimoto T, Taniwaki K. Acute popliteal artery occlusion after total knee arthroplasty. Arch Orthop Trauma Surg. 1997;116(6):429-30.

27 Hagan PF, Kaufman EE. Vascular complication of knee arthroplasty under tourniquet. A case report. Clin Orthop Relat Res. 1990;(257):159-61.

28 Boutchichi A, Ciornohac J, Daubresse F. Pseudoaneurysm after total knee arthroplasty: a rare complication with different possible clinical presentations. Acta Orthop Belg. 2013;79(1):16-9.

29 Gulhane S, Holloway I, Bartlett M. A vascular complication in computer navigated total knee arthroplasty. Indian J Orthop. 2013;47(1):98-100.

30 Wanken ZJ, Barnes JA, Eppolito AJ, Zwolak RM, Suckow BD. Coil embolization of an aberrant posterior tibial artery pseudoaneurysm after total knee arthroplasty. J Vasc Surg Cases Innov Tech. 2019;5(4):497-500.

31 Agarwala S, Menon A, Gupta M, Kulkarni A, Kapadia F, Padate B, et al. Multidimensional management of a vascular injury following total knee arthroplasty: a rare case report. J Clin Orthop Trauma. 2019;10(5):991-4.

32 Statz JM, Ledford CK, Chalmers BP, Taunton MJ, Mabry TM, Trousdale RT. Geniculate artery injury during primary total knee rthroplasty. Am J Orthop. 2018;47(10).

33 Darius Aw KL, Tan CC, Ch'ng JK, Chng SP. A case report of an anterior tibial artery pseudo-aneurysm open surgical management: a rare complication post total knee arthroplasty. Int J Surg Case Rep. 2017;37:196-9.

34 Zhao R, Li Y, Liu Y, Zhang K, Liu Z. Pseudoaneurysm of a high-division anterior tibial artery following primary TKA. Orthopade. 2017;46(3):275-9.

35 He R, Yang L. Acute arterial occlusion in the midpiece of femoral artery following total knee arthroplasty: report of one case. Chin J Traumatol. 2016;19(2):116-8.

36 Ammori MB, Evans AR, McLain AD. Popliteal artery pseudoaneurysm after total knee arthroplasty. J Arthroplasty. 2016;31(9):2004-7.

37 Woelfle-Roos JV, Dautel L, Wernerus D, Woelfle K-D, Reichel H. Vascular calcifications on the preoperative radiograph: predictor of ischemic complications in total knee arthroplasty? J Arthroplasty. 2016;31(5):1078-82.

38 Chikkanna JK, Sampath D, Reddy V, Motkuru V. Popliteal artery thrombosis after total knee replacement: an unusual complication. J Clin Diagn Res. 2015;9(11):RJ01-J2.

39 Ceulemans LJ, Deferm NP, Vanhoenacker FM, De Leersnyder J. Popliteal arteriovenous fistula following total knee arthroplasty. Acta Chirurgica Belgica. 2015;115(5):376-8.

40 Kehagias E, Ioannou CV, Kontopodis N, Balalis C, Tsetis D. Intraoperative endovascular stent-graft repair of a popliteal artery laceration and occlusion during total knee arthroplasty. Ann Vasc Surg. 2015;29(7):1453.e9-.e14.

41 Mathew A, Abraham BJ, Fischer L, Punnoose E. Popliteal artery thrombosis following total knee arthroplasty managed successfully with percutaneous intervention. BMJ Case Rep. 2014;2014:bcr2014206936.

42 Bernhoff K, Rudström H, Gedeborg R, Björck M. Popliteal artery injury during knee replacement. Bone Joint J. 2013;95-B(12):1645-9.

43 Mozella AP, da Palma IM, de Souza AF, Gouget GO, de Araújo Barros Cobra HA. Amputation after failure or complication of total knee arthroplasty: prevalence, etiology and functional outcomes. Rev Bras Ortop. 2013; 48(5):406-11.

44 Dossche L, Brabants KAM. Arterial graft occlusion after total knee arthroplasty treated by prompt thrombectomy. J Arthroplasty. 2002;17(5):670-2.

45 Mureebe L, Gahtan V, Kahn MB, Kerstein MD, Roberts AB. Popliteal artery injury after total knee arthroplasty. Am Surg. 1996;62(5):366-8.

46 Rush JH, Vidovich JD, Johnson MA. Arterial complications of total knee replacement. The Australian experience. J Bone Joint Surg Br. 1987;69(3):400-2.

47 Papas TT, Maltezos CK, Papanas N, Antoniou G, Lazarides MK. Popliteal artery pseudoaneurysm after total knee replacement. Vasa. 2007;36(2):145-8. 